\title{
P02-288
}

\section{INTERACTION OF PSYCHOLOGICAL AND NEUROBIOLOGICAL RISK FACTORS IN THE BACKGROUND OF SUICIDAL BEHAVIOR}

A. Szkaliczki, P.Z. Álmos, B. Andó, E. Krivek, J. Kálmán Jr., Z. Janka

Department of Psychiatry, Faculty of Medicine, University of Szeged, Szeged, Hungary

Aims: Many studies investigated social, psychological, existential and environmental risk factors in the background of suicidal behavior, while recent researches put emphasis on the neurobiological basis by revealing impairments in decision-making related to the ventromedial prefrontal cortex. In this ongoing study we aimed to integrate these approaches with examining the correlating factors of personality character traits, impulsivity and the function of ventromedial cortex.

Methods: 30 suicide attempters and 28 controls participated in our study. Data regarding the act of suicide, previous attempts, personal and family history, current medication and general health state were recorded. All participants received Temperament and Character Inventory (TCl) and Barratt Impulsivity Scale (BIS) and they were asked to perform the computerized version of lowa Gambling Task (IGT).

Results: Suicide attempters scored significantly higher on BIS. They achieved significantly higher harm avoidance and transcendence scores and lower self-directedness, social deviance and cooperation scores on $\mathrm{TCl}(p<0.05)$. Suicide attempters selected less advantageous desks on both reward and punishment sensitive tasks of IGT $(p<0.05)$. Significant correlation was found between novelty-seeking personality trait and punishment sensitivity $(p<0.05)$.

Conclusion: Our study supports the previous findings regarding the impairment of ventromedial cortex in the background of suicidal behavior. Furthermore, we demonstrated relation between this alteration and specific personality traits of suicide patients. This approach may shed light on the interaction of psychological and neurobiological risk factors. 